\title{
Identification and repair of intraoperative cerebrospinal fluid leaks in endonasal transsphenoidal pituitary surgery: surgical experience in a series of 1002 patients
}

\author{
Ben A. Strickland, MD, ${ }^{1}$ Joshua Lucas, MD, ${ }^{1}$ Brianna Harris, MD, ${ }^{1}$ Edwin Kulubya, MD, ${ }^{1}$ \\ Joshua Bakhsheshian, MD, ${ }^{1}$ Charles Liu, MD, ${ }^{1}$ Bozena Wrobel, MD, ${ }^{2}$ John D. Carmichael, MD, ${ }^{3}$ \\ Martin Weiss, MD, ${ }^{1}$ and Gabriel Zada, MD ${ }^{1}$
}

Departments of ${ }^{1}$ Neurosurgery, ${ }^{2}$ Otolaryngology, and ${ }^{3}$ Endocrinology, Keck School of Medicine, University of Southern California, Los Angeles, California

OBJECTIVE Cerebrospinal fluid (CSF) rhinorrhea is among the most common complications following transsphenoidal surgery for sellar region lesions. The aim of this study was to review the authors' institutional experience in identifying, repairing, and treating CSF leaks associated with direct endonasal transsphenoidal operations.

METHODS The authors performed a retrospective review of cases involving surgical treatment of pituitary adenomas and other sellar lesions at the University of Southern California between December 1995 and March 2016. Inclusion criteria included all pathology of the sellar region approached via a direct microscopic or endoscopic endonasal transsphenoidal approach. Demographics, pathology, intraoperative and postoperative CSF leak rates, and other complications were recorded and analyzed. A literature review of the incidence of CSF leaks associated with the direct endonasal transsphenoidal approach to pituitary lesions was conducted.

RESULTS A total of 1002 patients met the inclusion criteria and their cases were subsequently analyzed. Preoperative diagnoses included pituitary adenomas in 855 cases (85.4\%), Rathke's cleft cyst in 94 (9.4\%), and other sellar lesions in $53(5.2 \%)$. Lesions with a diameter $\geq 1 \mathrm{~cm}$ made up $49 \%$ of the series. Intraoperative repair of an identified CSF leak was performed in 375 cases (37.4\%) using autologous fat, fascia, or both. An additional 92 patients (9.2\%) underwent empirical sellar reconstruction without evidence of an intraoperative CSF leak. Postoperative CSF leaks developed in 26 patients $(2.6 \%)$, including $13(1.3 \%$ of the overall group) in whom no intraoperative leak was identified. Among the 26 patients who developed a postoperative CSF leak, 13 were noted to have intraoperative leak and underwent sellar repair while the remaining 13 did not have an intraoperative leak or sellar repair. No patients who underwent empirical sellar repair without an intraoperative leak developed a postoperative leak. Eight patients underwent additional surgery $(0.8 \%$ reoperation rate) for CSF leak repair, and 18 were successfully treated with lumbar drainage or lumbar puncture alone. The incidence of postoperative CSF rhinorrhea in this series was compared with that in 11 other reported series that met inclusion criteria, with incidence rates ranging between $0.6 \%$ and $12.1 \%$.

CONCLUSIONS In this large series, half of the patients who developed postoperative CSF rhinorrhea had no evidence of intraoperative CSF leakage. Unidentified intraoperative CSF leaks and/or delayed development of CSF fistulas are equally important sources of postoperative CSF rhinorrhea as the lack of employing effective CSF leak repair methods. Empirical sellar reconstruction in the absence of an intraoperative CSF leak may be of benefit following resection of large tumors, especially if the arachnoid is thinned out and herniates into the sella.

https://thejns.org/doi/abs/10.3171/2017.4.JNS162451

KEY WORDS CSF leak repair; complications; pituitary surgery; transsphenoidal

$\mathrm{T}$ HE transsphenoidal approach to the sellar region has long stood as the primary method used to access the pituitary gland, due to its high efficacy and low morbidity rate, even with large lesions. ${ }^{6,7}$ Although rates of morbidity associated with this technique have improved significantly over the last decade, complication rates can be as high as $22 \% .^{22}$ One of the most common complications associated with transsphenoidal surgery is cerebrospinal fluid (CSF) leakage. ${ }^{2}$ Recently, improved repair techniques have improved the incidence of postoperative

ABBREVIATIONS ACTH = adrenocorticotropic hormone; CSF = cerebrospinal fluid; GH = growth hormone; USC = University of Southern California .

SUBMITTED September 21, 2016. ACCEPTED April 4, 2017.

INCLUDE WHEN CITING Published online September 29, 2017; DOI: 10.3171/2017.4.JNS162451. 
CSF leaks, thereby minimizing the risk of associated tension pneumocephalus or meningitis. ${ }^{5}$ Evidence has shown that fat and/or fascia grafts harvested from the patient's abdomen or thigh are effective tools to control leaks that are identified intraoperatively and may obviate the need for lumbar drainage. Autologous grafting to reconstruct the floor of the sella turcica is not usually necessary unless an intraoperative CSF leak is encountered or there is evidence of a thin diaphragma sellae or extensive arachnoid herniation. ${ }^{6,21}$ We report our longstanding institutional experience and the effectiveness of a fat or fascial apposition graft to repair sellar defects in cases in which an intraoperative CSF leak is identified, paying special attention to the incidence and outcomes of postoperative CSF leaks.

\section{Methods}

All investigations were approved by the institutional review board of the Keck School of Medicine of USC (the University of Southern California). A retrospective medical chart review of 1002 cases of sellar region lesions (confirmed by pathology) treated by direct transsphenoidal approaches between December 1995 and March 2016 at USC was performed. Cases in which extended approaches were used were excluded from the analysis. There was no empirical use of intraoperative lumbar drainage. A Valsalva maneuver up to $40 \mathrm{~mm} \mathrm{Hg}$ was performed intraoperatively to assess for CSF leakage in each case. The fat and fascia used to repair the intraoperative leaks were harvested from the abdomen or lateral thigh. In most cases, the sella was packed with a fat graft and the sellar floor was reconstructed using a 2-layer fascial apposition method, as described by Couldwell et al. ${ }^{6}$ Postoperative fluid leaks upon provocation testing that were concerning for a CSF leak were confirmed with beta 2 transferrin. Patient demographic characteristics, tumor type, intraoperative leak rate, graft type, and postoperative leak rate and other postoperative complications were recorded.

A literature review of all articles published in the English language regarding a direct approach to endonasal, endoscopic, transsphenoidal surgery was performed with specific focus on postoperative CSF leak rates. Incidence of postoperative CSF leaks, intraoperative repair method, and other complications were recorded. Studies analyzing both direct and extended surgical approaches were excluded unless the results were reported such that the patients undergoing the direct approach could be discerned from the extended approach.

\section{Results}

One thousand two patients who underwent transsphenoidal surgery were identified in our database. There were 462 lesions (46.1\%) with diameters $<1 \mathrm{~cm}$ and 491 lesions (49.0\%) with diameters $\geq 1 \mathrm{~cm}$, while 49 (4.89\%) records lacked lesion size. The preoperative diagnosis was nonfunctional adenoma in 551 cases $(55 \%)$, growth hormone $(\mathrm{GH})$-secreting adenoma in $123(12.3 \%)$, prolactinoma in 84 (8.4\%), adrenocorticotropic hormone (ACTH)-secreting adenoma in 97 (9.7\%), Rathke's cleft cyst in 94 (9.4\%), and other lesions in 53 (5.2\%) (Table 1).
TABLE 1. Pathological findings in 1002 patients who underwent transsphenoidal surgery for resection of pituitary lesions

\begin{tabular}{lc}
\hline \multicolumn{1}{c}{ Pathology } & No. of Patients $(\%)$ \\
\hline Nonfunctional adenoma & $551(55)$ \\
\hline GH-secreting adenoma & $123(12.3)$ \\
\hline ACTH-secreting adenoma & $97(9.7)$ \\
\hline Prolactinoma & $84(8.4)$ \\
\hline Rathke's cleft cyst & $94(9.4)$ \\
\hline Other & $53(5.2)$ \\
\hline
\end{tabular}

Three hundred seventy-five patients (37.4\%) underwent intraoperative repair of an identified CSF leak with abdominal fat, fascia, or both. Of these patients, 161 (42.9\%) had lesions $\geq 1 \mathrm{~cm}$ and $201(53.6 \%)$ had lesions $<1 \mathrm{~cm}$; $13(3.5 \%)$ records lacked recorded lesion size. Additionally, 99 (26.4\%) patients had hormonally active lesions, and $233(62.1 \%)$ had nonfunctional pathology $(\mathrm{p}<0.005)$. The remaining 43 patients were diagnosed with other pathologies. An additional 92 patients (9.18\%) had empirical/ preventive sellar reconstruction without evidence of an intraoperative CSF leak. Thus a total of 467 patients (46.6\%) underwent intraoperative graft placement with either autologous fat, fascia, or a combined graft. In 267 (57.2\%) of these 467 cases, a fat graft alone was used; in 88 cases (18.8\%), a combined fat/fascia graft was used; and in 1 case $(0.2 \%)$, collagen dural substitute allograft was added to the combined graft. In 535 (53.4\%) of the patients in this case series there was no evidence of intraoperative CSF leak and no graft was placed.

Of the 1002 patients who underwent transsphenoidal resection of a pituitary lesion, postoperative CSF rhinorrhea developed in $26(2.59 \%)$. Of the 535 patients who were not noted to have an intraoperative leak and in whom no sellar repair was performed, 13 (2.42\%) developed a leak in the postoperative period. The remaining 13 leaks occurred among the 375 patients who developed an intraoperative leak and underwent sellar repair (3.47\% of that subgroup). Among these 13 patients with failed repairs, 7 had undergone intraoperative fat and fascia grafting while in the remaining 6 cases only fat was used. Of the 467 patients who underwent intraoperative graft placement, 13 developed postoperative rhinorrhea ( $2.8 \%$ repair failure rate). None of the 92 patients without intraoperative CSF leakage who underwent preventative sellar floor repair developed postoperative CSF leakage (Table 2).

Reoperation for CSF leak repair was required in 8 patients $(0.8 \%)$. Eight patients were successfully managed by temporary lumbar drainage alone, and the remaining 10 patients underwent serial lumbar punctures with resolution of CSF rhinorrhea.

In this series of patients, there were no cases of pneumocephalus or intraoperative mortalities. Meningitis occurred in 5 patients $(<1.0 \%), 3$ of whom had corresponding CSF leaks. One patient $(0.08 \%)$ died in the 1st postoperative week of a pulmonary embolus after discharge from the hospital. One patient died of acute respiratory distress syndrome in the setting of severe sepsis. 
TABLE 2. Comparison of intraoperative findings and postoperative outcomes in this series of 1002 patients

\begin{tabular}{ccccr}
\hline $\begin{array}{c}\text { Postop } \\
\text { CSF } \\
\text { Leak }\end{array}$ & $\begin{array}{c}\text { Intraop CSF } \\
\text { Leak, Intraop } \\
\text { Graft Placed }\end{array}$ & $\begin{array}{c}\text { No Intraop } \\
\text { Leak, Intraop } \\
\text { Graft Placed }\end{array}$ & $\begin{array}{c}\text { No Intraop } \\
\text { Leak, No } \\
\text { Graft Placed }\end{array}$ & Total \\
\hline Present & 13 & 0 & 13 & 26 \\
\hline Absent & 362 & 92 & 522 & 976 \\
\hline Total & 375 & 92 & 535 & 1002 \\
\hline
\end{tabular}

\section{Discussion}

Transsphenoidal surgery is the standard treatment for sellar lesions, made popular by its high success rate and relatively low morbidity rate. ${ }^{6,7}$ One of the most common postoperative complications following transsphenoidal surgery for sellar region lesions is CSF leakage, which has reported to occur in up to $15 \%$ of cases (range $0.8 \%-15 \%$ ), with most authors citing an incidence rate of $1 \%-4 \% .^{2,4-9,}$ 11,12,15-19,22,23,25 Recent advancements and new techniques (e.g., the pedicled nasoseptal flap) have significantly decreased the number of intraoperative and postoperative CSF leaks, which in turn have decreased other serious complications such as pneumocephalus and meningitis. ${ }^{13}$ The current study reviewed the 20-year experience in 1002 patients at a single institution using a combination of fat/fascial apposition repair techniques, leading to an overall postoperative CSF leak rate of $2.6 \%$. In this series of cases, the reoperation rate for CSF leak repair was $0.8 \%$.

The other salient finding resulting from this study is that $50 \%$ of all postoperative CSF leaks (13 of 26 leaks) developed in patients in whom there was no intraoperative identification of a leak and in whom no sellar floor repair was performed. This implies that in patients who were noted to have a postoperative CSF leak without identification of an intraoperative CSF leak, the leak was either not identified or developed in a delayed fashion. In the 92 patients who underwent sellar repair without identification of an intraoperative CSF leak, there were no cases of postoperative rhinorrhea.

Other authors have reported the routine use of lumbar drainage or lumbar fenestration with intrathecal fluorescein administration for routine pituitary surgery. ${ }^{17,20} \mathrm{Al}$ though an argument for routine utilization of intrathecal fluorescein can be made based on the fact that half of our postoperative CSF leaks were not identified intraoperatively, it remains impossible to discern which leaks were missed during surgery and would have been identified if fluorescein were employed, versus those that developed in a delayed fashion (e.g., upon extubation). Based on our low incidence of postoperative CSF rhinorrhea (2.6\%) and our even lower incidence of repeat surgery for leak repair $(0.8 \%)$, we do not feel that routine use of lumbar drainage or fluorescein is warranted for direct approaches to the sella (nonextended approaches). For extended approaches, we often use a fascial apposition repair in conjunction with lumbar drainage and a pedicled nasoseptal flap.

For many years, neurosurgeons have opted to reconstruct the floor of the sella turcica using autologous fat, fascia, muscle, turbinate grafts, or synthetic products following transsphenoidal surgery in an effort to minimize and prevent postoperative leakage. . $3,4,8-12,14-16,18,19,23,25 \mathrm{Re}-$ cently, authors have argued that planned reconstruction in all patients was unnecessary and that results were comparable if sellar defect repair was only performed in patients with evidence of an intraoperative leak. ${ }^{6,21,24}$ This avoided second incisions in the abdomen and lowered both hospital stay and complication rates.

\section{Incidence of CSF Leak and Repair}

Most authors would agree that the most effective way to prevent a postoperative leak is to identify CSF leakage intraoperatively. ${ }^{17}$ The most effective form of intraoperative management, however, is still widely debated. Numerous studies have been published regarding the utilization of the direct endoscopic endonasal transsphenoidal approach for pituitary lesions. . $^{1,3,4,8,9,11,12,15-18,21,23,25}$ Studies have focused on operative technique, outcomes, and complications, with the majority of studies reporting incidence rates for postoperative CSF leak ranging from $0.6 \%$ to $12.1 \%$ (Table 3). The majority of intraoperative CSF leak repair strategies have used a combination of autologous fat or fascial grafts, synthetic dural grafts, and mesh devices with varying degrees of success.

Cappabianca et al. ${ }^{3}$ reported the surgical outcomes for 146 cases of pituitary adenomas, the majority of which were macroadenomas, with an overall postoperative CSF leak incidence of $3.7 \%$. There was no mention of intraoperative repair methods of CSF leaks. Similarly, Charalampaki et al. ${ }^{4}$ and Dallapiazza et al. ${ }^{8}$ reported large case series of 134 and 90 pituitary adenoma resections, respectively. Incidence of postoperative CSF leak was reported to be $3.3 \%$ in the series by Charalampaki et al., and $2.5 \%$ in the series by Dallapiazza et al. Again, no description of intraoperative CSF leak repair was provided. Mehta and Oldfield ${ }^{17}$ suggested that placement of a lumbar drain to minimize tension of the arachnoid is effective in reducing intraoperative CSF leak by $52 \%$, although the rate of postoperative CSF leaks did not differ between the patients who received a lumbar drain and those who did not. Sciarretta and colleagues ${ }^{21}$ reported on 665 patients who underwent resection of pituitary adenomas and only had fat and mucoperiosteum grafts placed if leaks were identified intraoperatively. In their study, 128 patients (19.2\%) required intraoperative repair of a CSF leak and $11(8 \%)$ required repair of a postoperative CSF leak.

Frank et al. ${ }^{11}$ used nasal packing in the event of intraoperative CSF leakage in a series of 380 patients, the majority of which had macroadenomas, with a leak rate of $1.2 \%$. Dehdashti et al. ${ }^{9}$ reported the results of 200 cases, mostly of macroadenomas, in which autologous fat and fascia grafts were used in the event of intraoperative CSF leak; postoperative leaks occurred in $3.5 \%$ of cases. Similarly, Berker et al. ${ }^{1}$ reported a $1.3 \%$ incidence of postoperative CSF leak with autologous fat and fascia grafts. Messerer et al. ${ }^{18}$ reported the outcomes of 82 cases (lesion sizes were not reported), citing a $12.1 \%$ incidence of postoperative CSF leak using the autologous fat and fascia grafts in addition to a synthetic dural graft. Zhan et al. ${ }^{25}$ experienced a $3.9 \%$ incidence of postoperative CSF leak with the ad- 
TABLE 3. Previously reported case series of direct endonasal endoscopic transsphenoidal surgeries

\begin{tabular}{|c|c|c|c|c|c|}
\hline Authors \& Year & $\begin{array}{l}\text { No. of } \\
\text { Cases }\end{array}$ & Pathology & Macro/Micro & $\begin{array}{l}\text { CSF } \\
\text { Leak }\end{array}$ & Repair Method \\
\hline Cappabianca et al., 2002 & 146 & NFA: 80; functional: 66 & Macro: 125; micro: 21 & $3.70 \%$ & None described \\
\hline Frank et al., 2006 & 380 & NFA: 173; functional: 207 & Macro: 294; micro: 86 & $1.20 \%$ & Nasal packing in $22 \%(n=84)$ \\
\hline Dehdashti et al., 2008 & 200 & NFA: 111; functional: 89 & Macro: 158; micro: 42 & $3.50 \%$ & Autologous fat \& fascia graft \\
\hline Charalampaki et al., 2009 & 134 & NFA: 59; functional: 75 & Macro: 60; micro: 74 & $3.30 \%$ & None described \\
\hline Gondim et al., 2011 & 301 & NFA: 135; functional: 166 & Macro: 248; micro: 53 & $2.60 \%$ & $\begin{array}{l}\text { Autologous fat \& fascia graft, mucoperiosteum w/ } \\
\text { possible nasal septal flap }\end{array}$ \\
\hline Messerer et al., 2011 & 82 & NFA: 24; functional: 58 & - & $12.10 \%$ & Autologous fat or fascia graft w/ synthetic dural graft \\
\hline Berker et al., 2012 & 570 & NFA: 153; functional: 417 & Macro: 437; micro: 133 & $1.30 \%$ & Autologous fat \& fascia graft \\
\hline Dallapiazza et al., 2015 & 80 & NFA: 75; functional: 0 & Macro: $27 ;$ micro: 55 & $2.50 \%$ & None described \\
\hline Wang et al., 2015 & 1166 & NFA: 577; functional: 589 & Macro: 921; micro: 245 & $0.60 \%$ & Duragen, Duraform, BioGlue \\
\hline Zhan et al., 2015 & 158 & - & Macro: 133; micro: 25 & $3.90 \%$ & $\begin{array}{l}\text { Autologous fat or fascia graft w/ synthetic dural graft } \\
\text { \& muscle }\end{array}$ \\
\hline Magro et al., 2016 & 300 & NFA: 300; functional: 0 & - & $2.70 \%$ & $\begin{array}{l}\text { Autologous fat } w / \text { dural substitute or titanium mesh } \\
\text { w/ dural substitute }\end{array}$ \\
\hline Present study & 1002 & NFA: 683; functional: 319 & Macro: 491; micro: 462 & $2.59 \%$ & Autologous fat \& fascia graft \\
\hline
\end{tabular}

Macro = macroadenoma; micro = microadenoma; NFA = nonfunctional adenoma

dition of synthetic dural grafts to autologous fat and fascial grafts. Gondim et al. ${ }^{12}$ also used the autologous fat and fascial graft, with the addition of a nasoseptal flap in the majority of cases. The overall incidence of postoperative CSF leak was noted to be $2.6 \%$ across 301 pituitary adenomas, the majority of which were classified as macroadenomas. Wang et al. ${ }^{23}$ reported the largest known case series of pituitary lesions, with a total of 1166 cases, 921 of which were classified as macroadenomas. Intraoperative CSF leaks were repaired with the use of Duragen (Integra), overlying Duraform (DePuy Synthes), and BioGlue (CryoLife). The overall incidence of postoperative CSF leak was $0.6 \%$. Magro et al. ${ }^{16}$ reported the results of 300 cases of pituitary lesions in which intraoperative CSF leaks were repaired by means of either a titanium mesh with dural substitute or autologous fat and fascia grafts. The incidence of postoperative CSF leaks was noted to be $2.7 \%$.

\section{Present Series}

In our series of cases, an apposition graft was placed in every instance of an identified intraoperative leak. In 92 patients, an intraoperative graft was placed in the absence of CSF leakage, usually in cases of large exposure or herniation of the arachnoid. The incidence of intraoperative leak was $37.4 \%$, and the postoperative leak incidence was $2.6 \%$. Patients with identified intraoperative leaks underwent graft placement with fat, fascia, or both. Of these 375 patients who underwent graft placement, only 13 patients developed a postoperative CSF leak, indicating a $96.5 \%$ success rate on first attempt. Graft failure occurred in $2.8 \%$ of patients, and the remaining 13 patients developing postoperative CSF leaks were not identified to have intraoperative CSF leaks and did not undergo graft placement. Among the patients with a "missed" diagnosis of intraoperative leak, it is unknown whether the postoperative leak can be attributed to delayed leak development or the presence of an unrecognized intraoperative leak, despite not being apparent during intraoperative Valsalva maneuvers. Seven of these patients had a macroadenoma with visible arachnoid at the time of closure, supporting the hypothesis that there was a delayed leak. Nevertheless, 8 patients in our series required a reoperation, another 8 were managed by lumbar drain placement alone, and the remaining 10 were treated with serial lumbar punctures, indicating that despite missing a small percentage of intraoperative leaks, the current method is superior to others currently practiced.

\section{Other Complications}

In addition to a low rate of CSF leakage, there was no increased incidence of meningitis $(<1.0 \%)$ in this series when compared with the literature. ${ }^{1,22}$ In a study of 570 patients, Berker et al. ${ }^{1}$ reported an overall complication rate of $12.1 \%$. In their series, there were 5 cases of meningitis $(0.8 \%)$. Similarly, in a study by Persky et al., ${ }^{19}$ there were 3 cases of meningitis $(0.82 \%)$. The overall incidence of meningitis after transsphenoidal pituitary resection ranges from $0 \%$ to $9 \%$, indicating that the incidence of meningitis in this series is consistent with, if not lower than that reported in the literature. ${ }^{1,22,24}$

The death rate in this series $(0.2 \%)$ was lower than that reported in the literature. In the meta-analysis of 821 patients, the overall mortality rate was $0.24 \%{ }^{22}$ while another study of 354 patients reported an overall mortality rate of $0.8 \% . .^{19}$ Our results are consistent with the literature, indicating no increased risk of mortality with our proposed technique. We acknowledge that this review was retrospective and therefore limited in scope.

\section{Conclusions}

Our surgical series is among the largest studies of CSF leak incidence in patients undergoing direct endonasal 
transsphenoidal surgery to date. Our data suggest that prevention and identification of CSF leakage may be as critical an issue as intraoperative CSF leak repair. Additionally, based on our findings, we recommend using an intraoperative graft or other mechanism of repair if extensive arachnoid herniation is evident following tumor resection, even without identification of an overt intraoperative CSF leak. Finally, our data demonstrate that if an intraoperative leak is identified, the fat/fascial apposition method is extremely effective in successfully repairing the defect and preventing postoperative CSF leakage and other complications.

\section{References}

1. Berker M, Hazer DB, Yucci T, Gurlek A, Cila A, Aldur M, et al: Complications of endoscopic surgery of the pituitary adenomas: analysis of 570 patients and review of the literature. Pituitary 15:288-300, 2012

2. Black PM, Zervas NT, Candia GL: Incidence and management of complications of transsphenoidal operation for pituitary adenomas. Neurosurgery 20:920-924, 1987

3. Cappabianca P, Cavallo LM, Esposito F, Valente V, De Divitiis E: Sellar repair in endoscopic endonasal transsphenoidal surgery: results of 170 cases. Neurosurgery 51:13651372, 2002

4. Charalampaki P, Ayyad A, Kockro RA, Perneczky A: Surgical complications after endoscopic transsphenoidal pituitary surgery. J Clin Neurosci 16:786-789, 2009

5. Ciric I, Ragin A, Baumgartner C, Pierce D: Complications of transsphenoidal surgery: results of a national survey, review of the literature, and personal experience. Neurosurgery 40:225-237, 1997

6. Couldwell WT, Kan P, Weiss MH: Simple closure following transsphenoidal surgery. Technical note. Neurosurg Focus 20(3):E11-E13, 2006

7. Cusimano MD, Kan P, Nassiri F, Anderson J, Goguen J, Vanek I, et al: Outcomes of surgically treated giant pituitary tumours. Can J Neurol Sci 39:446-457, 2012

8. Dallapiazza RF, Grober Y, Starke RM, Laws ER Jr, Jane JA Jr: Long-term results of endonasal endoscopic transsphenoidal resection of nonfunctioning pituitary macroadenomas. Neurosurgery 76:42-53, 2015

9. Dehdashti AR, Ganna A, Karabatsou K, Gentili F: Pure endoscopic endonasal approach for pituitary adenomas: early surgical results in 200 patients and comparison with previous microsurgical series. Neurosurgery 62:1006-1017, 2008

10. Esposito F, Dusick JR, Fatemi N, Kelly DF: Graded repair of cranial base defects and cerebrospinal fluid leaks in transsphenoidal surgery. Neurosurgery 60 (4 Suppl 2):295-304, 2007

11. Frank G, Pasquini E, Farneti G, Mazzatenta D, Sciarretta V, Grasso V, et al: The endoscopic versus the traditional approach in pituitary surgery. Neuroendocrinology 83:240248, 2006

12. Gondim JA, Almeida JP, Albuquerque LA, Schops M, Gomes E, Ferraz T, et al: Endoscopic endonasal approach for pituitary adenoma: surgical complications in 301 patients. Pituitary 14:174-183, 2011

13. Hadad G, Bassagasteguy L, Carrau RL, Mataza JC, Kassam A, Snyderman CH, et al: A novel reconstructive technique after endoscopic expanded endonasal approaches: vascular pedicle nasoseptal flap. Laryngoscope 116:1882-1886, 2006

14. Kaptain GJ, Kanter AS, Hamilton DK, Laws ER: Management and implications of intraoperative cerebrospinal fluid leak in transnasoseptal transsphenoidal microsurgery. Neurosurgery 68 (1 Suppl Operative):144-151, 2011
15. Lee JY, Bohman LE, Bergsneider M: Contemporary neurosurgical techniques for pituitary tumor resection. J Neurooncol 117:437-444, 2014

16. Magro E, Graillon T, Lassave J, Castinetti F, Boissonneau S, Tabouret E, et al: Complications related to the endoscopic endonasal transsphenoidal approach for nonfunctioning pituitary macroadenomas in 300 consecutive patients. World Neurosurg 89:442-453, 2016

17. Mehta GU, Oldfield EH: Prevention of intraoperative cerebrospinal fluid leaks by lumbar cerebrospinal fluid drainage during surgery for pituitary macroadenomas. J Neurosurg 116:1299-1303, 2012

18. Messerer M, De Battista JC, Raverot G, Kassis S, Dubourg J, Lapras V, et al: Evidence of improved surgical outcome following endoscopy for nonfunctioning pituitary adenoma removal. Neurosurg Focus 30(4):E11, 2011

19. Persky MS, Brunner E, Cooper PR, Cohen NL: Perioperative complications of transseptosphenoidal excision for pituitary adenomas. Skull Base Surg 6:231-235, 1996

20. Raza SM, Banu MA, Donaldson A, Patel KS, Anand VK, Schwartz TH: Sensitivity and specificity of intrathecal fluorescein and white light excitation for detecting intraoperative cerebrospinal fluid leak in endoscopic skull base surgery: a prospective study. J Neurosurg 124:621-626, 2016

21. Sciarretta V, Mazzatenta D, Ciarpaglini R, Pasquini E, Farneti G, Frank G: Surgical repair of persisting CSF leaks following standard or extended endoscopic transsphenoidal surgery for pituitary tumor. Minim Invasive Neurosurg 53:55-59, 2010

22. Tabaee A, Anand VK, Barrón Y, Hiltzik DH, Brown SM, Kacker A, et al: Endoscopic pituitary surgery: a systematic review and meta-analysis. J Neurosurg 111:545-554, 2009

23. Wang F, Zhou T, Wei S, Meng X, Zhang J, Hou Y, et al: Endoscopic endonasal transsphenoidal surgery of 1,166 pituitary adenomas. Surg Endosc 29:1270-1280, 2015

24. Wang YY, Kearney T, Gnanalingham KK: Low-grade CSF leaks in endoscopic trans-sphenoidal pituitary surgery: efficacy of a simple and fully synthetic repair with a hydrogel sealant. Acta Neurochir (Wien) 153:815-822, 2011

25. Zhan R, Ma Z, Wang D, Li X: Pure endoscopic endonasal transsphenoidal approach for nonfunctioning pituitary adenomas in the elderly: surgical outcomes and complications in 158 patients. World Neurosurg 84:1572-1578, 2015

\section{Disclosures}

The authors report no conflict of interest concerning the materials or methods used in this study or the findings specified in this paper.

\section{Author Contributions}

Conception and design: Strickland, Lucas, Harris, Kulubya, Bakhsheshian, Liu, Zada. Acquisition of data: Strickland, Lucas, Harris, Kulubya, Bakhsheshian. Analysis and interpretation of data: Strickland, Lucas, Liu, Wrobel, Carmichael, Weiss, Zada. Drafting the article: all authors. Critically revising the article: Strickland, Lucas, Bakhsheshian, Liu, Wrobel, Carmichael, Weiss, Zada. Reviewed submitted version of manuscript: all authors. Approved the final version of the manuscript on behalf of all authors: Strickland. Statistical analysis: Strickland, Lucas, Zada. Administrative/technical/material support: Strickland, Lucas, Zada. Study supervision: Liu, Zada.

\section{Correspondence}

Ben Strickland, Department of Neurosurgery, Keck School of Medicine of USC, 1200 North State St., Ste. 3300, Los Angeles, CA 90089. email: ben.strickland@med.usc.edu. 